\title{
Digital Response During the COVID-19 Pandemic in Saudi Arabia
}

Marwah Hassounah ${ }^{1}$, MBBS, MPH; Hafsa Raheel ${ }^{1}$, MBBS, FCPS, MCPS; Mohammed Alhefzi ${ }^{2,3}$, MD, SBCM-HI, MSc, FAIDH

\footnotetext{
${ }^{1}$ Prince Sattam Chair for Epidemiology and Public Health Research, Department of Family and Community Medicine, College of Medicine, King Saud University, Riyadh, Saudi Arabia

${ }^{2}$ Preventive Medicine and Clinical Informatics, King Faisal Medical City for Southern Regions, Abha, Saudi Arabia

${ }^{3}$ Saudi Association for Health Informatics, Riyadh, Saudi Arabia
}

\section{Corresponding Author:}

Hafsa Raheel, MBBS, FCPS, MCPS

Prince Sattam Chair for Epidemiology and Public Health Research, Department of Family and Community Medicine

College of Medicine

King Saud University

Room No. 321/27, Third Floor

Medical Education Department

Riyadh,

Saudi Arabia

Phone: 966556942926

Email: hafsaraheel@yahoo.com

\section{Abstract}

Background: The first case of COVID-19 in Saudi Arabia was confirmed on March 3, 2020. Saudi Arabia, like many other countries worldwide, implemented lockdown of most public and private services in response to the pandemic and established population movement restrictions nationwide. With the implementation of these strict mitigation regulations, technology and digital solutions have enabled the provision of essential services.

Objective: The aim of this paper is to highlight how Saudi Arabia has used digital technology during the COVID-19 pandemic in the domains of public health, health care services, education, telecommunication, commerce, and risk communication.

Methods: We documented the use of digital technology in Saudi Arabia during the pandemic using publicly available official announcements, press briefings and releases, news clips, published data, peer-reviewed literature, and professional discussions.

Results: Saudi Arabia's government and private sectors combined developed and launched approximately 19 apps and platforms that serve public health functions and provide health care services. A detailed account of each is provided. Education processes continued using an established electronic learning infrastructure with a promising direction toward wider adoption in the future. Telecommunication companies exhibited smooth collaboration as well as innovative initiatives to support ongoing efforts. Risk communication activities using social media, websites, and SMS text messaging followed best practice guides.

Conclusions: The Saudi Vision 2030 framework, released in 2017, has paved the path for digital transformation. COVID-19 enabled the promotion and testing of this transition. In Saudi Arabia, the use of artificial intelligence in integrating different data sources during future outbreaks could be further explored. Also, decreasing the number of mobile apps and merging their functions could increase and facilitate their use.

(J Med Internet Res 2020;22(9):e19338) doi: $\underline{10.2196 / 19338}$

\section{KEYWORDS}

digital response; COVID-19; Saudi Arabia; digital health; containment; public health; pandemic; prevention

\section{Introduction}

The outbreak of SARS-CoV-2, emerging from the markets of Wuhan, led to the COVID-19 pandemic [1,2]. The current population-wide measures of home quarantine that were simultaneously applied worldwide to slow and prevent the spread of COVID-19 are unprecedented. The COVID-19 pandemic has caused disruption of daily services due to the community-wide mitigation measures taken by many countries. Due to the low likelihood of obtaining a vaccine in the near future, global efforts have vastly focused on social distancing and complete city and state lockdowns in many instances as the 
only solutions to contain the pandemic [3]. These mitigation measures have necessitated the use of technology to maintain functions in all aspects of life.

The global experiences with the H1N1 influenza pandemic in 2009 [4] and Ebola virus in 2014 clearly indicated that timely and appropriate technology usage played a considerable role in controlling these pandemics [5-7]. A cloud computing tool for data collection and integration for confirmed cases of Middle East respiratory syndrome coronavirus (MERS-CoV), a GPS-based risk assessment tool [8], and Google Maps usage for the geographical representation of MERS-CoV cases worldwide are examples of the technological methods used to control the outbreak of Middle East respiratory syndrome (MERS) [8]. By establishing a national electronic surveillance system $[9,10]$, Saudi Arabia also contributed to the global data pool of MERS-CoV information.

During the current COVID-19 pandemic, Saudi Arabia has been proactive in implementing disease containment measures and working to meet the community's needs and demands in a very short time [3]. It is currently estimated that 30,260,000 people in Saudi Arabia (89\% of the population) use the internet, $96 \%$ of the population uses smartphones [11], and the majority of the population now has access to smartphones, laptop computers, desktop computers, and tablets; therefore, digital service provision is much easier than in the past and has aided the mitigation efforts established by the government.
Keeping in view the importance of quick and timely digital data sharing for policy actions, which is also emphasized by the World Health Organization (WHO) [12], our aim in this paper is to highlight how Saudi Arabia has used digital technology during the COVID-19 pandemic.

\section{Methods}

The authors documented Saudi Arabia's experience using publicly available official announcements, press briefings and releases, news clips, published data, peer-reviewed literature, and professional discussions. The searched information sources were in both English and Arabic languages. A literature search was conducted from March 20 to June 20, 2020. Each author collected, examined, and synthesized information on a designated sector; then, all the authors consolidated, discussed, and agreed on the final findings. The inclusion criteria for information were that the information depicted a prominent event during the COVID-19 pandemic response, included technology or digitalization, and was specific to Saudi Arabia. The findings are mainly presented in narrative form.

\section{Results}

Figure 1 and Table 1 visualize and summarize some of the applications and platforms used for various health sectors during the COVID-19 pandemic in Saudi Arabia.

Figure 1. Examples of digital apps available for various health care domains during the COVID-19 pandemic in Saudi Arabia.

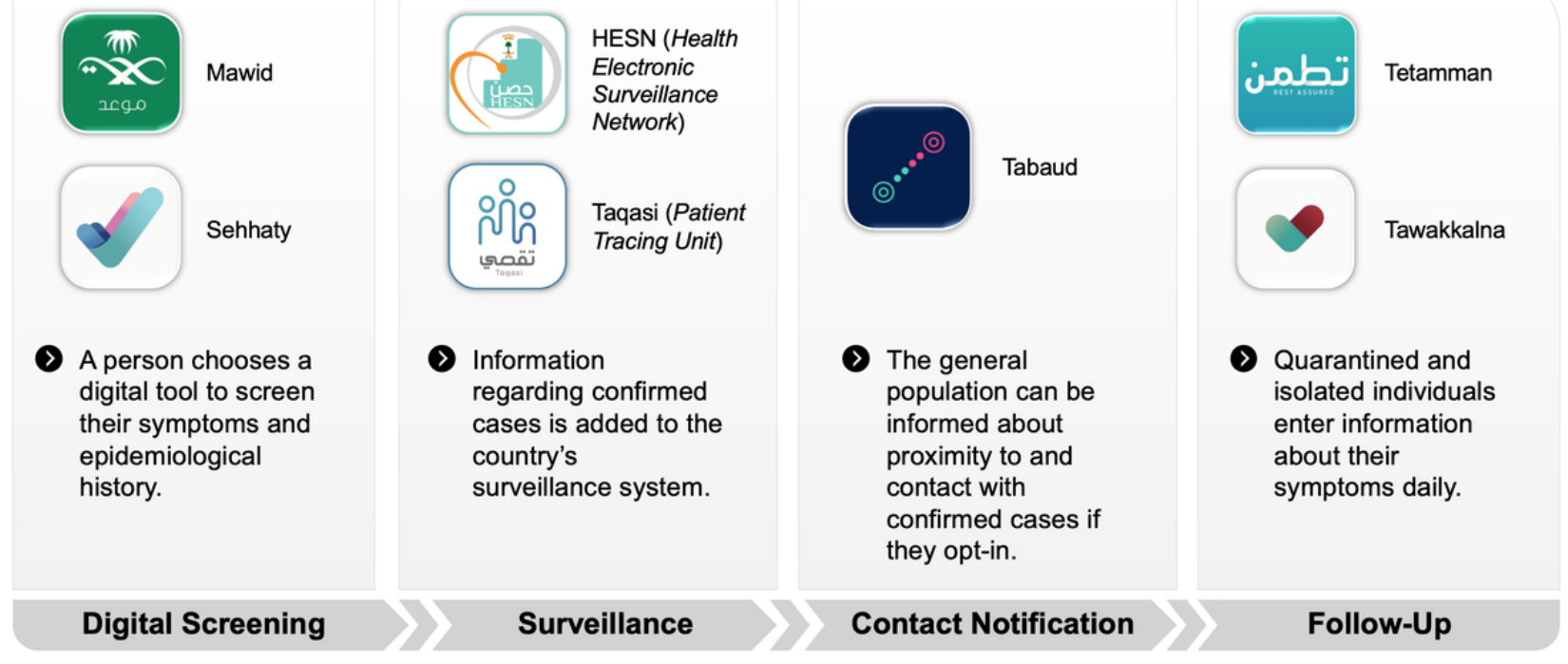


Table 1. Summary of telehealth applications available in Saudi Arabia during the COVID-19 pandemic.

\begin{tabular}{|c|c|c|c|}
\hline Name & Type & Short description & Provider \\
\hline Sehha [13] & $\begin{array}{l}\text { Smartphone app (iOS/An- } \\
\text { droid) }\end{array}$ & $\begin{array}{l}\text { Teleconsultation (synchronous live video chat, nonsyn- } \\
\text { chronous SMS text messaging). }\end{array}$ & Ministry of Health \\
\hline \multirow[t]{2}{*}{ Mawid [14] } & \multirow{2}{*}{$\begin{array}{l}\text { Smartphone app (iOS/An- } \\
\text { droid), web-based applica- } \\
\text { tion }\end{array}$} & $\begin{array}{l}\text { Symptom checker/appointment gateway to all Saudi } \\
\text { Ministry of Health Services. }\end{array}$ & \multirow[t]{2}{*}{ Ministry of Health } \\
\hline & & $\begin{array}{l}\text { Used as the main channel for the virtual COVID-19 } \\
\text { screening/triaging by the Saudi Ministry of Health. }\end{array}$ & \\
\hline Anat [15] & $\begin{array}{l}\text { Smartphone app (iOS/An- } \\
\text { droid) }\end{array}$ & $\begin{array}{l}\text { E-prescription }{ }^{\mathrm{a}} \text { gateway; licensure of all health care } \\
\text { professionals is checked with the Saudi Commission } \\
\text { for Health Specialties. }\end{array}$ & Ministry of Health \\
\hline Wasfaty [16] & Web-based & $\begin{array}{l}\text { The official e-prescription gateway provided by the } \\
\text { Ministry of Health. }\end{array}$ & Ministry of Health \\
\hline Asefni [17] & $\begin{array}{l}\text { Smartphone app (iOS/An- } \\
\text { droid) }\end{array}$ & $\begin{array}{l}\text { GPS-enabled requests for emergency services nation- } \\
\text { wide. }\end{array}$ & Saudi Red Crescent Authority \\
\hline Cura [18] & $\begin{array}{l}\text { Smartphone app (iOS/An- } \\
\text { droid) }\end{array}$ & $\begin{array}{l}\text { Teleconsultations (synchronous live video chat, non- } \\
\text { synchronous SMS text messaging, more specific sub- } \\
\text { specialties/for-profit). }\end{array}$ & Private \\
\hline MayaClinic [19] & $\begin{array}{l}\text { Smartphone app (iOS/An- } \\
\text { droid) }\end{array}$ & $\begin{array}{l}\text { Teleconsultations (nonsynchronous text messaging } \\
\text { with health care providers). }\end{array}$ & Private \\
\hline Nala [20] & $\begin{array}{l}\text { Smartphone app (iOS/An- } \\
\text { droid) }\end{array}$ & $\begin{array}{l}\text { Teleconsultations (artificial intelligence-enabled } \\
\text { chatbot provides decision support for the public, acts } \\
\text { as an appointment gateway and nonsynchronous mes- } \\
\text { saging with health care providers). }\end{array}$ & Private \\
\hline Labayh [21] & $\begin{array}{l}\text { Smartphone app (iOS/An- } \\
\text { droid) }\end{array}$ & $\begin{array}{l}\text { Teleconsultations (mainly provides psychology ses- } \\
\text { sions and mental health services). }\end{array}$ & Private \\
\hline 80/20 Lifestyle [22] & $\begin{array}{l}\text { Smartphone app (iOS/An- } \\
\text { droid) }\end{array}$ & $\begin{array}{l}\text { Remote patient engagement and lifestyle change rec- } \\
\text { ommendations. }\end{array}$ & Private \\
\hline $\begin{array}{l}\text { Virtual Medical Academy } \\
\text { [23] }\end{array}$ & $\begin{array}{l}\text { Web-based interactive } \\
\text { academy }\end{array}$ & $\begin{array}{l}\text { Videoconferencing events targeted to health care pro- } \\
\text { fessionals. }\end{array}$ & Private \\
\hline SCFHS Webinars [24] & Web-based seminars & $\begin{array}{l}\text { Offers support services to health care professionals } \\
\text { under their programs (Daem for residents and Emtenan } \\
\text { for all health care professionals). }\end{array}$ & $\begin{array}{l}\text { Saudi Commission for Health } \\
\text { Specialties }\end{array}$ \\
\hline
\end{tabular}

ae-prescription: electronic prescription.

\section{Health Sector Digitalization}

Amid the COVID-19 pandemic, the Saudi Ministry of Health has implemented multiple informatics tools to provide public health information for individuals as well as the community.

\section{Public Health Informatics Tools}

In 2018, the Ministry of Health launched a national central health care appointment gateway through a mobile app and web-based application called Mawid, which translates to "Appointment" [14] (Figure 1). Soon after, in August 2019, the Sehhaty ("My Health") app was launched in the pursuit of a wide range of health promotional campaigns that target healthy lifestyles, using gamification and community-wide challenges [25]. However, both apps were updated to respond to the COVID-19 pandemic by introducing a symptom checker to enable people who suspect they have COVID-19 to directly book appointments at dedicated COVID-19 clinics [26] and drive-through mass testing locations around the Kingdom [27].

For COVID-19 surveillance, the Health Electronic Surveillance Network (HESN) has been mainly used as a reliable source of

data for all COVID-19 laboratory tests in the Kingdom. The HESN serves as a national communicable disease surveillance platform. It was launched in 2012 and piloted during the largest public health event in Saudi Arabia: the annual pilgrimage season, or the Hajj [28]. Moreover, the Patient Tracing Unit (Taqasi) platform was implemented in March 2020 for the COVID-19 pandemic. Its purpose is to enhance and manage contact tracing around the Kingdom based on the laboratory results generated from the HESN.

Locally published preventative and clinical guidelines give directions for home isolation with documented daily follow-ups and for tracking symptoms for mild cases and contacts. To provide these functions, the National Health Emergency Operation Centre launched a smartphone app, Tetamman, which translates as "Rest Assured" [29]. In May 2020, the Ministry of Health announced that the Tetamman app will also be associated with a smart bracelet for individuals returning from abroad as well as those who are isolated in their homes [30].

Contact tracing has been termed as an essential epidemiologic tool for containing the COVID-19 outbreak and enforcing future plans for lifting lockdown safely. To achieve this, the Saudi 
Data and Artificial Intelligence Authority (SDAIA) released two smartphone apps. The first is Tawakkalna, a GPS-enabled app to monitor and restrict individuals' movement during curfew hours with the capacity to issue permits for exceptions. The second app, Tabaud, whose name means "Distancing" [31], sends deidentified data to people who came in close contact with confirmed cases of COVID-19. The app follows the international Google and Apple guidelines on data privacy.

\section{Health Care Delivery}

The Saudi Ministry of Health (MOH), as the main health care provider in the Kingdom of Saudi Arabia, is looked upon as the main source of authentic and reliable health information for the Saudi population. Other channels of health care delivery include the Ministry of Defense, university teaching hospitals, and the private sector. Similarly, tertiary, secondary, and primary care facilities provide health care to both nationals and nonnationals. In 2011, the Saudi MOH agreed upon a vision to improve the standards, equitability, availability, and quality of health care in the Kingdom of Saudi Arabia by the use of electronic communication and information technology in this sector. The Vision 2030 National Transformation Program [32] health care strategic objectives for the years 2018 to 2020 aimed to increase access to care, improve quality, and promote the prevention of health risks. It highlights electronic health (eHealth) as an essential enabler to the health care transformation; hence, it tasks the National Health Information Centre with creating multisectoral coherent eHealth services. During the aforementioned community-wide measures to combat the spread of COVID-19, the government of Saudi Arabia and the private health care sector activated existing digital health solutions and produced new ones.

The MOH Call (937) Service Center was established to answer inquiries related to COVID-19. Moreover, one hospital initiated a remotely controlled robot for rounding and monitoring of intensive care unit patients [33].

For hospitals that had teleconsultation apps in place before COVID-19, whether well-established or in pilot phases, some activated their apps to serve patients who do not require in-person hospital visits, such as King Saud Medical City in the public sector and Dr Sulaiman Al Habib Medical Group in the private sector. The group messaging app WhatsApp remains the preferred messaging app in the Kingdom [11]; some hospitals and medical cities in the Eastern Region, such as Qatif Central Hospital and its primary care centers, initiated WhatsApp numbers to help patients register their medication refill requests, arrange for remote routine follow-ups, and inquire regarding their laboratory results.

Periods of pandemics have been shown to cause a surge in stress related to fear of the unknown and isolation. Hence, the literature highlights the need for establishment of psychological support to communities during such periods. To achieve this objective, the National Centre for Mental Health Promotion collaborated with the developers of a local mobile counselling app, Labayh, to provide free sessions for people experiencing anxiety and panic symptoms in the current situation [21]. In another instance, the Saudi Commission for Health Specialties (SCFHS) nationally launched a set of mental health support services for all health care professionals in the Kingdom under its Emtenan initiative as well as for residents in training (Daem) [24]. The SCFHS not only called its registered health care professionals but also sent them SMS text messages, enquiring about their safety and advising them to keep safe.

In the area of telepharmacy, the $\mathrm{MOH}$ and other tertiary health care facilities sent medications to patients' homes via courier companies or established telepharmacy services [15]. Furthermore, the MOH sent out SMS text reminders to all health care providers with active professional registration to use its electronic prescription (e-prescription) services in collaboration with private sector pharmacies. One example is the Anat mobile app [15], which enables providers to directly electronically prescribe medications to patients by credentialed and licensed providers. Other apps that have been active in recent years in Saudi Arabia are Wasfaty [16], translated as "My Prescription," which is the official gateway for e-prescriptions under the Ministry of Health's free services, and the Sehha [13] mobile teleconsultation app, which can provide patients with e-prescriptions via SMS text message following a medical consultation with a physician. Private telehealth services such as Cura [18] and Maya Clinic [19] are offering similar services either freely or with modest charges to support their COVID-19 efforts.

With the success of telemedicine services, King Salman bin Abdulaziz Al Saud of Saudi Arabia issued a royal decree to amend health professionals' practice regulations to allow telemedicine use for diagnostic and management purposes from the workplace and at home. This royal order also directs all relevant sectors to amend their regulations to accommodate this change [34].

\section{Educational Sector Digitalization}

According to Saudi national statistics [35], approximately $1,353,619$ students are enrolled in 28 governmental and 34 private higher education institutes. Moreover, there are approximately 5000 schools in the Kingdom that provide secondary level education; these include both public and private sector institutions.

Electronic learning (e-learning) is not new in the Kingdom. Its first decade (1990-2000) in Saudi Arabia's education system was supported well by the evolution of computer technology and the World Wide Web [36]. By 2002, Saudi Arabia had established a national school e-learning platform with tailored electronic lessons [36]. The following years witnessed expansion and enhancement of e-learning in collaboration with international partners [36]. In 2017, as part of Vision 2030, the Ministry of Education (MOE) established the National Center for e-Learning [37]. This center serves to supervise and support eLearning in Saudi Arabia. The current COVID-19 pandemic poses immense challenges to maintaining continuity of educational services across the Kingdom. This challenge was most evident in the health educational sector due to the absence of a standard and unified method of eLearning and because educational methods depend on patient interactions.

It is already known that major universities in the Kingdom such as King Saud University, Taibah University, King Khalid 
University, Qassim University, Islamic University of Madinah, Al-Baha University, and King Abdul-Aziz University are the most active e-learning university partners in the Kingdom. However, higher education institutions were challenged by the COVID-19 situation to continue tutoring and assessment of technical skills [38]. Hence, universities offered different methods of e-learning support depending on the course requirements and interim assessment needs [39].

Later, the Minister of Education congratulated higher educational institutes on their successful shift to distance learning since the COVID-19 outbreak. The universities reported that collectively, 1.2 million users were conducting 107,000 hours of web-based learning in more than 7600 virtual classes [40]. The MOE also directed higher education students and faculty to its website "Shams," an open education resource.

The aforementioned SCFHS is Saudi Arabia's accreditation and registration body for health care professionals. It offers a series of accredited educational webinars for continuing medical education hours. The SCFHS has collaborated with local and international platforms such as Virtual Medical Academy [23], UpToDate [41], and MDBriefcase [42]. The topics listed therein include a COVID-19 overview, physician burnout, a COVID-19 critical care crash course, and ethical issues during pandemics using COVID-19 as an example [43]. Other nonprofit public and private initiatives have followed the SCFHS's lead $[43,44]$.

It is worth noting that all educational institutions, including higher education institutions, continued delivery of education during lockdown. Both public and private institutions used various two-way e-learning methods to continue teaching and student learning. This ranged from individual institute-based platforms such as Blackboard and McGraw-Hill Connect to common commercial platforms such as Zoom, Google Class, and FaceTime.

An interesting and unique step taken by the MOE was to shift public school education to its distant learning portals, namely Ein (translated as "Eye") and Vschool.sa [45]. Ein, which was launched by the Ministry of Education before the COVID-19 outbreak, features a television channel that broadcasts daily lessons based on the national curriculum [39]. During the COVID-19 pandemic, the Ein channel and a corresponding YouTube channel have been redirected to provide live tutoring of all school level subjects and lessons daily from 8:30 AM to 12 PM on weekdays [46]. This great effort was conducted by 127 teachers in 112 subjects. Ein also provides a website through which students can practice lesson exercises and communicate with their teachers [46]. The vschool.sa portal is unique to Saudi Arabia and is a unified learning portal by the Ministry of Education that complements Ein. It provides synchronized web-based tutoring, assessment tools, learning material, and apps for smartphone access [47].

\section{Telecommunication, Commercial, and Miscellaneous Digital Services}

The major telecom companies in Saudi Arabia, namely the Saudi Telecom Company (STC), Mobily, and Zain Saudi Arabia, have announced free-of-charge data services to the most used educational platforms as well as health and telehealth applications to facilitate the smooth delivery of e-learning as well as health care delivery during the pandemic. The expected high usage of internet services, which exceeded the current capacity by around $33 \%$, was also supported by the Saudi Communication and Information Technology Commission (CITC), which developed related infrastructure to accommodate the sudden high demand [36]. In an unprecedented move, prior to the COVID-19 pandemic, the CITC had also launched a guide to inform consumers about the trusted available mobile apps that are officially registered within the commission [48]. Internet providers also enabled users to access the Ministry of Health and governmental educational websites without consuming their personal data. When a call is placed on an STC or Mobily mobile number, a voice recording plays that reiterates Ministry of Health messages to help prevent the spread of COVID-19. Telecom companies changed their network names to display a message saying "Stay Home" (Figure 2). All these measures contributed to health education and the awareness drive. 
Figure 2. Instagram advertisement for the new symptom checker feature on the Saudi Ministry of Heath's scheduling mobile app.

\section{Instagram}

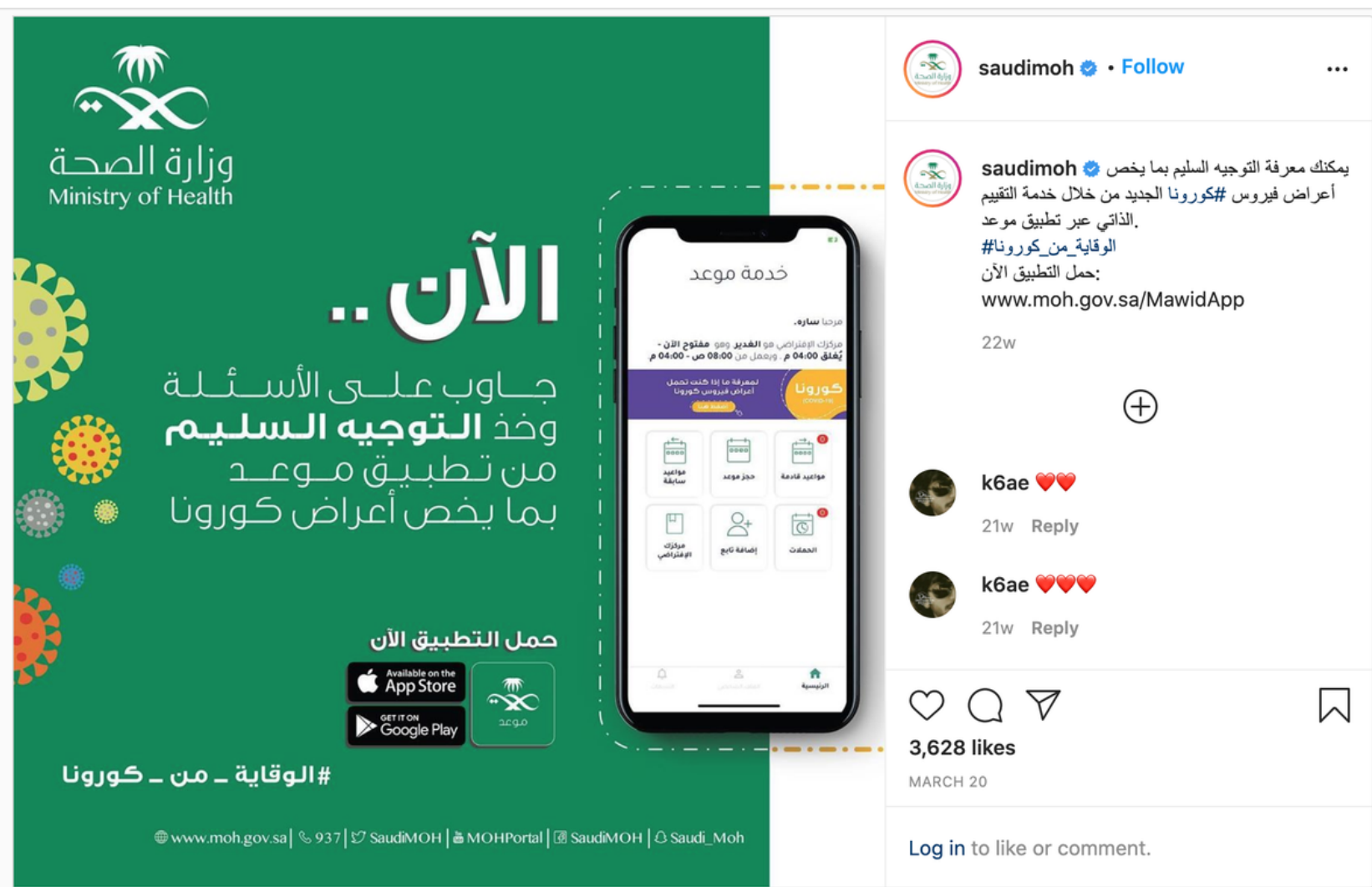

One of the most notable initiatives in Saudi Arabia is "Move to Tech." This initiative was launched by the Saudi Ministry of Communications and Information Technology on March 10, 2020 [49]. It facilitates the use of current digital tools and the creation of new ones in response to COVID-19. This has increased the use of digital tools in several sectors, but mainly in education, the food industry and health care. Following this initiative, a COVID-19 Hackathon [50] was launched to provide innovative remote and virtual solutions to combat the pandemic.
The G20 International Economic Leaders' Summit, scheduled in March 2020 and hosted by Saudi Arabia, was required to "go digital" in light of the COVID-19 pandemic. The summit hosted 19 countries, the European Union, and the Central Bank Governors. Saudi Arabia initiated the G20 Extraordinary Virtual Leaders' Summit on COVID-19 using videoconferencing that was inclusive of all international delegates. It is worth mentioning that the platform used was built and coordinated by the SDAIA (Figure 3) [51,52].

Figure 3. Snapshot of the G20 Extraordinary Virtual Leaders' Summit on COVID-19, hosted by the Saudi King Salman Bin Abdulaziz, on March 26, 2020 .

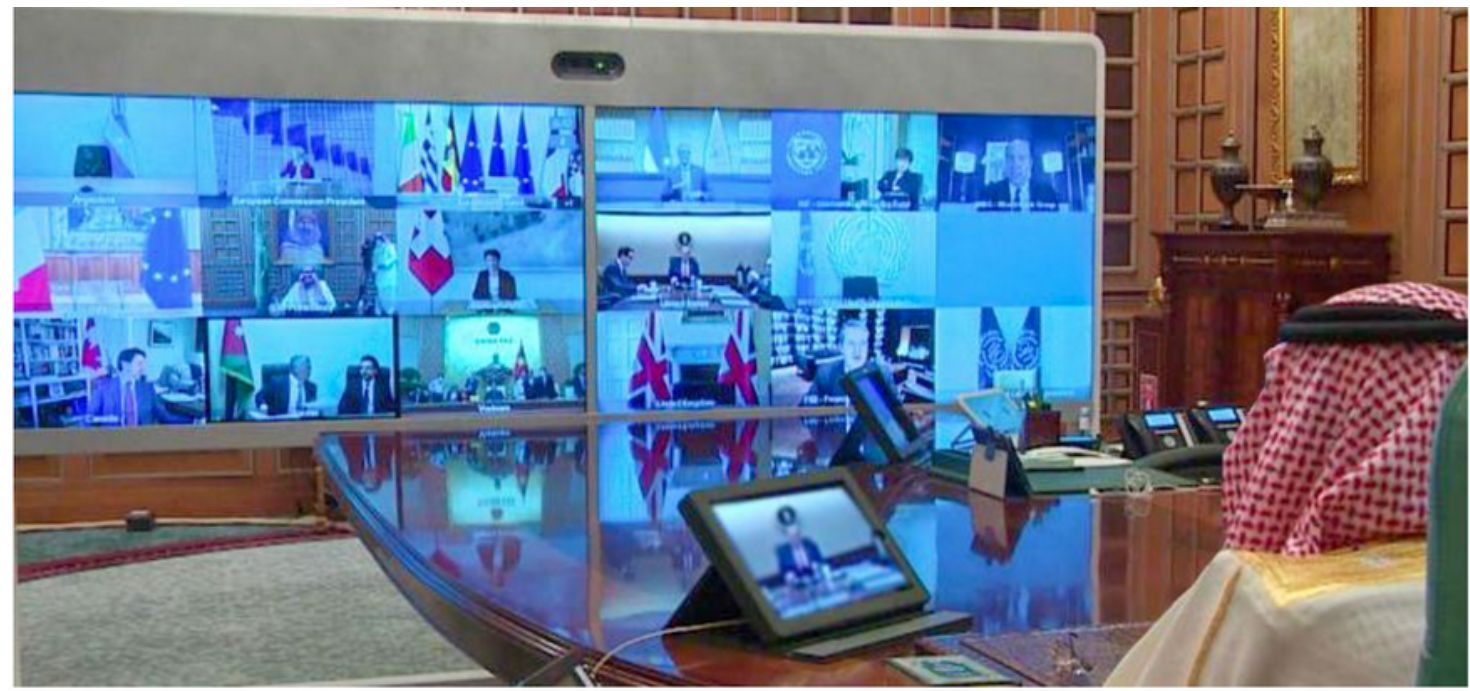


In 2018, the Saudi Red Crescent Authority launched a mobile app, "Asefni," which translates to "Save Me." The aim of this app was to facilitate emergency service requests with accurate GPS locations [17]. When strict local curfew and travel restrictions were imposed on all Saudi citizens, the app was updated to provide movement permits during the curfew order for individuals who required essential medical consultations. This permit is issued for each case only after an initial web-based assessment [53]. Similarly, Saudi Public Security launched an online portal, "Tanaqul," to receive requests for domestic land travel permits between cities for people with extenuating circumstances [54].

Electronic commerce, on the other hand, was a prosperous industry in the Kingdom even before COVID-19. Major retailers had established web-based ordering and home delivery services throughout the major cities for everyday grocery items, home essentials, and furniture. The community-wide quarantine has highlighted the role of these web-based commercial services in aiding the mitigation process.

\section{Risk Communication Directed at the Public Through Social Media}

The year 2011 witnessed a boom of social media and user-generated content in Saudi Arabia [55]. The current social media scene in Saudi Arabia with regard to the percentage of internet users shows that the most preferred and used social media platforms are YouTube, WhatsApp, Facebook, Instagram, and Twitter [11]. In April 2011, the Saudi Ministry of Health joined Twitter and successfully built its audience's trust over the years until it reached nearly 3 million followers in early 2020 [56,57]. Before the first confirmed case of COVID-19 in Saudi Arabia, the $\mathrm{MOH}$ used its website and social media platforms, including Twitter, Facebook, YouTube, Snapchat, Instagram, and TikTok, to distribute health education materials.
Different formats were used, such as WhatsApp stickers for proper hygiene. The topics included what COVID-19 is, how it is transmitted, how to prevent getting it, and where it originated. As the pandemic progressed and new scenarios emerged, the literature was modified and expanded to accommodate these changes. It was also translated into other languages, including but not limited to English, Portuguese, French, Russian, Tagalog, Spanish, and Urdu, ensuring a wider spread of relevant information [58]. The $\mathrm{MOH}$ and other ministries also used SMS text messages in both English and Arabic to raise awareness and emphasize the practice of precautions. Regular messages were sent to all citizens in different languages.

After the first case of COVID-19 in Saudi Arabia was confirmed on March 3, 2020, the Twitter account of the official spokesperson of the MOH was activated to directly and quickly announce and respond to COVID-19 news [59]. Rumors and misinformation are an expected and organic part of risk communication. According to the WHO, the best practices to address rumors and misinformation in risk and crisis communication include prevention, monitoring, and strategies for approaching a rumor when it occurs [60]. The spokesperson of the MOH incorporated this WHO strategy of dissolving original rumors. On Twitter, he would retweet the rumor with a comment to directly spread the correct information [59]. Figure 4 shows a comment by the MOH spokesperson on a widely distributed tweet by a person who was concerned about a colleague at his school who had just come back from Iran and had shown symptoms of respiratory illness [61]. The spokesperson thanked him for his concern and reassured him that the MOH had reached out to the person of concern and tested him for the virus, and he was found to be negative. He concluded by asking all people to communicate similar concerns to the MOH call center. 
Figure 4. Twitter reply by the Saudi Ministry of Health spokesperson to a tweet by a person who was concerned about a colleague who showed symptoms of respiratory illness after returning from Iran [62].

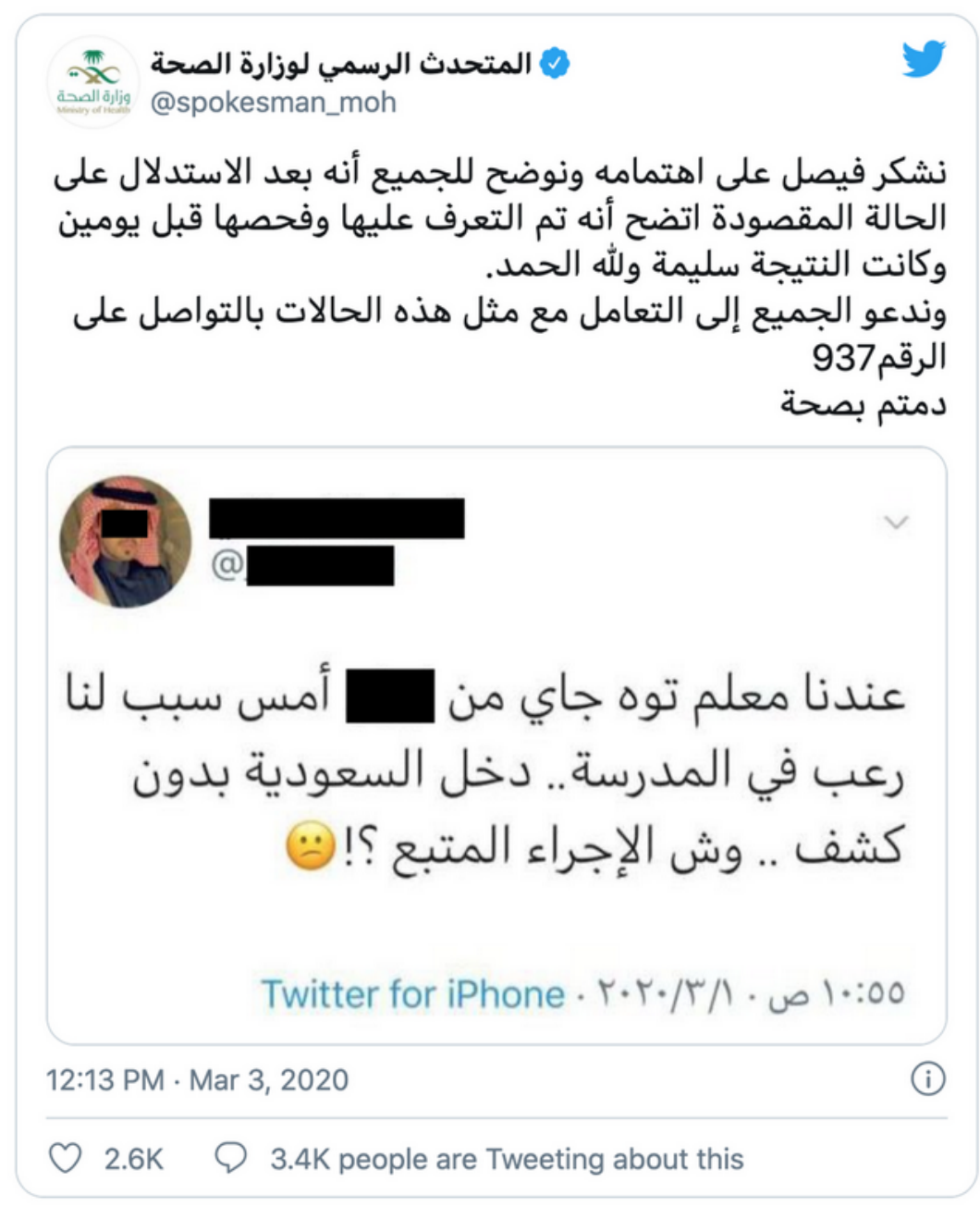

The MOH has also collaborated with other government and nongovernment health entities to establish the Prevention Ambassador Initiative. The initiative is a web-based course for the layperson that provides certification in baseline information on COVID-19 to help prevent and control the COVID-19 infodemic [63]. Another effort to contain internet rumors and misinformation is a Saudi Public Prosecution release stating that intentional spread of rumors about COVID-19 or sharing material that causes panic among the public is an electronic crime that can be punished with up to 5 years of imprisonment or a fine of SR 3 million (US \$799,888.20) [64].

When curfews were established in a number of major cities, the Center for Government Communication launched a national social media campaign titled Kollona Masool, meaning "We Are All Responsible" [65]. The main message of the campaign was that people should stay at home as a patriotic duty to their country and fellow residents. This hashtag was widely used by officials and the general population, and government entities on Twitter changed their cover images to read Kollona Masool.
At this point, global brands were separating their logos and Twitter user names to emphasize social distancing. Many Saudi government entities and community influencers did the same. Once the lockdown was gradually lifted, this campaign shifted to Naoodo bi Hathar, which means "Return Carefully."

Early in the pandemic, the Saudi Health Council and the National Health Information Center started the first Arabic web-based interactive map dedicated to COVID-19 [66] (Figure 5). The map regularly updates travel alerts, confirmed cases, treated cases, deaths, percentage of treated cases, and percentage of deaths. The map is available as an app on the Apple Store [67]. It has an artificial intelligence (AI)-enabled chatbot, "Bashayar," that offers simple guidance in simple language. It also has a pop-up news headline with the latest official Arabic news on COVID-19 and a dropdown menu with further resources, including educational material, statistics, graphs, sources, data sets, isolation hospitals, statuses of major local and international conferences, and other studies [66]. 


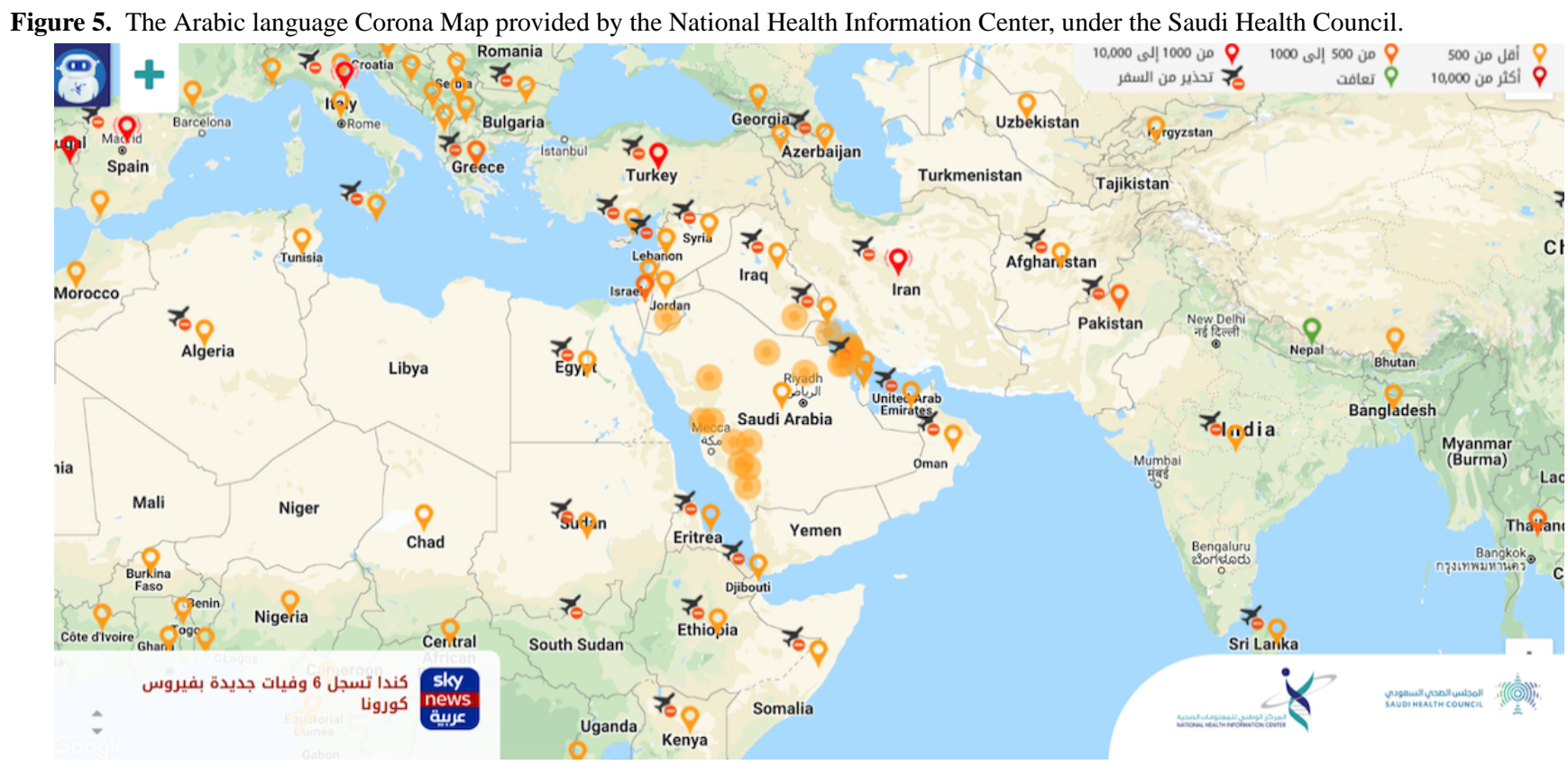

As more cases were discovered, the National Centre for Disease Prevention and Control (NCDC), also known as Weqaya, launched the COVID-19 hub website, followed by the Ministry of Health's COVID-19 awareness website [68]. Here, Arabic guidelines and essential information could be found under broad audience categories: community and public, professionals and health care workers, and daily updates [69]. A month into COVID-19 containment measures, the Ministry of Health released a public link to its live local Arabic dashboard, COVID-19 Dashboard: Saudi Arabia [69]. Accessibility to credible facts in a timely manner are core WHO principles of risk communication [60].

\section{Discussion}

\section{Principal Findings}

The ways in which the world has attempted to respond digitally to COVID-19 have surely raised concerns about how the world may be transformed post-COVID-19. On one hand, the need for digital response has been significantly highlighted; on the other hand, major challenges associated with its usage have surfaced [62]. We have already witnessed historical success stories in which countries used technology such as electronic databases and Google Maps to curb the spread of outbreaks.

Even in the current pandemic, several success stories have surfaced in which technology usage helped save lives when global markets shut down and strict curfews were enacted. The United Kingdom, for instance, initiated a COVID-19 symptom tracker app that allows users to enter their symptoms for risk identification, referral, and follow-up [70]. The use of mobile data has been suggested to help identify people at greater risk of travel-related infectious disease and in directing mass screening efforts accordingly. Google and Apple [71] introduced a decision support tool that acts as a location checker and has been implemented in the Tabaud app. Location data gathered from smartphones is used by public health officials to track patterns of movement of quarantined or home-isolated individuals.
A recent article published in The Lancet [72] highlighted the use of AI in curbing COVID-19. Taiwan used AI to improve its national health insurance database and integrate it with its immigration and customs database to create Big Data for analytics and crossmatching of individuals. This system generated alerts during clinical visits based on travel history and clinical symptoms to aid case identification. It also used QR-code scanning and web-based reporting of travel history and health symptoms to classify travelers' infectious risks based on their flight origins and travel histories for the past 14 days. Persons with low risk (no travel to Level 3 alert areas) were sent a health declaration border pass to their phones via SMS text message for faster immigration clearance; those with higher risk were quarantined at home and tracked through their mobile phones to ensure they remained at home during the incubation period [73].

The use of telehealth and chatbots in the United States and Singapore has shown promising results in enabling remote triaging of care and providing rapidly accessible information; these measures enable the provision of care to patients without requiring them to leave their homes $[74,75]$.

Saudi Arabia's digital response to the COVID-19 pandemic is noteworthy. The aforementioned digital tools of public health and health care services are on par with those used worldwide. A few areas still require more exploration, such as the use of AI. It may be desirable to connect all the governmental and nongovernmental apps created during the COVID-19 pandemic to effectively activate interoperability across different technologies. This can lead to the creation of large, continuously updated data sets, which can be later used for diagnosis, management, and policy implementation.

However, we do recommend decreasing the number of public health mobile apps available for use during a future outbreak. This is to decrease the burden on the end user, avoid confusion, and ensure better adherence. As mentioned previously, there are five applications for COVID-19 symptoms and history screening, follow-up of cases, and contact tracing. Last, it should 
be ensured that digital location identifiers activated via these applications do not breach privacy and agreed-upon permissions, as both Apple and Google have raised concerns regarding adherence to Health Insurance Portability and Accountability Act (HIPPA) regulations [76].

Wuhan was the first city to implement complete lockdown and initiate the policy of "Suspend Classes Without Stopping Learning." Lessons from this policy show the importance of having a strong web-based teaching infrastructure, the necessity of building the capacity of teachers, and finding solutions to bridge up the information gap that may occur because of distance teaching [77]. Fortunately, Saudi Arabia already possessed public and private e-learning infrastructure at the time of the COVID-19 pandemic. Saudi universities conducted webinars and training to rapidly increase their faculty's capacity for e-learning [78]. In one of the MOE's COVID-19 webinars, a group of education experts found that the COVID-19 experience proved successful in breaking educators' psychological barriers to use technology and distant learning methods. They also highlighted the future potential of e-learning to enhance web-based question banks and electronic resources, further engage faculty, adopt remote administrative meetings, decrease costs, and improve outcomes [79]. The Minister of Education hinted that distance learning would be made part of the Kingdom's regular education system [80], as it appears to be the new norm.

The main challenge posed by the COVID-19 pandemic has been the provision of efficient, accurate, and timely information to populations at risk worldwide [81]. The experience of COVID-19 risk communication by the Saudi Ministry of Health was perceived as very useful by $72 \%$ and very satisfactory by $74 \%$ of a survey population of 3133 Twitter users [82]. Through previous evaluation and improvement efforts, as well as experience with MERS-CoV, the risk communication infrastructure for this pandemic had already been built. Previous literature showed the types and sources of information that people in Saudi Arabia were seeking during the MERS-CoV outbreak. One study showed that $40 \%$ of people preferred the internet as a source of information [83].

In 2017, Saudi Arabia underwent a WHO Joint External Evaluation for international health risk assessment, including risk communication. This evaluation documented the use of the
$\mathrm{MOH}$ web-based social listening tool to monitor rumors and adapt messaging according to the audience [84]. Similarly, Finland used social media messages and email to thematically categorize the community response to COVID-19 and develop recommendations for evidence-based risk communication [85]. Here, we urge the Ministry of Health to document its risk communication experience with COVID-19 for future reference, decision making, and simulation training.

Despite Saudi Arabia's widespread usage of various technical platforms during the current pandemic, this experience of learning and sharing seems to be ongoing. The community shift toward digital solutions will unravel further challenges and advantages as we continue to control and mitigate the epidemic curve. The implications and impact of this shift are yet to be known and studied. Whether the emerged digital dynamics and new norms among different sectors should be continued after the end of community quarantine remains unanswered.

\section{Limitations}

We attempted to encompass all digital solutions and tools used during the COVID-19 outbreak in Saudi Arabia up to the time of manuscript revision; however, shortcomings are expected. The COVID-19 pandemic is a rapidly changing scenario with weekly updates. This paper also lists apps but does not evaluate them or check for user experiences. Moreover, the criteria for inclusion in this paper were subjective. The authors attempted to decrease the effect of this subjectivity using discussion and consensus.

\section{Conclusion}

Saudi Arabia has been working to digitally transform many of its sectors since the launch of the national agenda, Vision 2030, in 2017 [32]. The COVID-19 pandemic has expedited this transformation. It has tested the reliability of the country's digital infrastructure and has highlighted questionable gaps for decision makers. This has been a nationwide trial of Saudi citizens' acceptance and ability to use and engage with the digitalization of these services and communications. At this point, it is too early to evaluate the unique Saudi experience of population-wide digital solutions. Future research should further explore and analyze the successes and pitfalls, hindrances, and challenges of this digital experience for specific sectors, including institutions, employees, and consumers.

\section{Acknowledgments}

The authors are grateful to the Deanship of Scientific Research, King Saud University, for funding through the Vice Deanship of Scientific Research Chairs. The authors would like to acknowledge Mrs Sadia Javaid for her help in editing the manuscript.

\section{Conflicts of Interest}

None declared.

\section{References}

1. Q\&A on coronaviruses (COVID-19). World Health Organisation. 2020 Mar 09. URL: https://www.who.int/news-room/ q-a-detail/q-a-coronaviruses [accessed 2020-08-24]

2. Wu Z, McGoogan JM. Characteristics of and Important Lessons From the Coronavirus Disease 2019 (COVID-19) Outbreak in China: Summary of a Report of 72314 Cases From the Chinese Center for Disease Control and Prevention. JAMA 2020 Feb 24;323(13):1239-1242. [doi: 10.1001/jama.2020.2648] [Medline: 32091533] 
3. Hilton T. Countries with coronavirus curfews: Saudi Arabia joins growing list. Alarabia. 2020 Mar 23. URL: https://english. alarabiya.net/en/features/2020/03/23/Countries-with-coronavirus-curfews-Saudi-Arabia-joins-growing-list [accessed 2020-08-24]

4. Past pandemics. World Health Organization Regional Office for Europe. URL: http://www.euro.who.int/en/health-topics/ communicable-diseases/influenza/pandemic-influenza/past-pandemics [accessed 2020-07-24]

5. Cleary V, Balasegaram S, McCloskey B, Keeling D, Turbitt D. Pandemic (H1N1) 2009: setting up a multi-agency regional response centre--a toolkit for other public health emergencies. J Bus Contin Emer Plan 2010 Mar;4(2):154-164. [Medline: 20494880]

6. Wilson C, Jumbert MG. The new informatics of pandemic response: humanitarian technology, efficiency, and the subtle retreat of national agency. Int J Humanitarian Action 2018 May 30;3(1):8. [doi: 10.1186/s41018-018-0036-5]

7. Chew C, Eysenbach G. Pandemics in the age of Twitter: content analysis of Tweets during the 2009 H1N1 outbreak. PLoS One 2010 Nov 29;5(11):e14118 [FREE Full text] [doi: 10.1371/journal.pone.0014118] [Medline: 21124761]

8. Sandhu R, Sood SK, Kaur G. An intelligent system for predicting and preventing MERS-CoV infection outbreak. J Supercomput 2016;72(8):3033-3056 [FREE Full text] [doi: 10.1007/s11227-015-1474-0] [Medline: $\underline{\text { 32214655] }}$

9. Middle East respiratory syndrome coronavirus (MERS-CoV) 2019. World Health Organization. 2019. URL: https://www. who.int/en/news-room/fact-sheets/detail/middle-east-respiratory-syndrome-coronavirus-(mers-cov) [accessed 2020-08-24]

10. Saeed AAB, Abedi GR, Alzahrani AG, Salameh I, Abdirizak F, Alhakeem R, et al. Surveillance and Testing for Middle East Respiratory Syndrome Coronavirus, Saudi Arabia, April 2015-February 2016. Emerg Infect Dis 2017 Apr;23(4):682-685 [FREE Full text] [doi: 10.3201/eid2304.161793] [Medline: 28322710]

11. Digital 2019 Saudi Arabia. 2019 Jan 30. URL: https://www.slideshare.net/DataReportal/ digital-2019-saudi-arabia-january-2019-v01 [accessed 2020-08-25]

12. Germann S. World Health Day: Digital and data's role in the COVID-19 response. Foundation Botinar. 2020 Apr 07. URL: https://www.fondationbotnar.org/world-health-day-digital-and-datas-role-in-the-covid-19-response/ [accessed 2020-08-25]

13. Sehha App. Apple App Store. URL: https://apps.apple.com/sa/app/\%D8\%B5\%D8\%AD\%D9\%87/id1205814003 [accessed 2020-08-25]

14. Mawid E Services 2020. Saudi Ministry of Health. URL: https://www.moh.gov.sa/en/eServices/Pages/cassystem.aspx [accessed 2020-08-25]

15. Al-Rabiah: Doctors can Issue Prescriptions via Anaat App. Saudi Ministry of Health. 2020 Mar 26. URL: https://www. moh.gov.sa/en/Ministry/MediaCenter/News/Pages/News-2020-03-26-003.aspx [accessed 2020-08-25]

16. Wasfaty. URL: https://wasfaty.sa [accessed 2020-08-25]

17. National Digital Transformation Annual Report 2019. Digital Saudi. URL: https://ndu.gov.sa/report/ndu-annual-report-en. pdf [accessed 2020-08-25]

18. Cura App. Cura Healthcare. URL: https://company.cura.healthcare/en/ [accessed 2020-05-20]

19. Maya Clinic. URL: http://www.mayaclinic.com/ [accessed 2020-08-25]

20. Nala - Talk to a doctor. Webpage in Arabic. URL: https://nala.ai/ [accessed 2020-08-25]

21. Labyah counseling sessions. Webpage in Arabic. Labyah. 2020. URL: https://www.labayh.net/login [accessed 2020-08-25]

22. 80/20 Lifestyle App. Webpage in Arabic. URL: https://80-20app.com/ [accessed 2020-08-25]

23. Virtual Medical Academy. Webpage in Arabic. URL: https://medicalacademy.org/portal/ [accessed 2020-08-25]

24. Daem Service 2020. Saudi Comission for Health Speacialities. URL: https://www.scfhs.org.sa/en/eservices/trainees/Pages/ TrainingGuidanceServiceDesc.aspx [accessed 2020-06-20]

25. Al-Rabiah Highlights Updates of Transformation Programs and Initiatives 2020. Saudi Ministry of Health. 2019 Sep 10. URL: https://www.moh.gov.sa/en/Ministry/MediaCenter/News/Pages/News-2019-09-10-003.aspx [accessed 2020-08-25]

26. (Tetamman)Clinics at Healthcare Centers and Hospitals. Saudi Ministry of Health. 2020. URL: https://www.moh.gov.sa/ en/HealthAwareness/Tataman-Clinics/Pages/default.aspx [accessed 2020-08-25]

27. Public Health: Expanding Testing. Saudi Ministry of Health. URL: https://www.moh.gov.sa/en/HealthAwareness/ EducationalContent/PublicHealth/Pages/Expanded_Testing.aspx [accessed 2020-08-25]

28. Alotaibi B, Yezli S, Bin Saeed AAA, Turkestani A, Alawam A, Bieh K. Strengthening health security at the Hajj mass gatherings: characteristics of the infectious diseases surveillance systems operational during the 2015 Hajj. J Travel Med 2017 May 01;24(3):taw087 [FREE Full text] [doi: 10.1093/jtm/taw087] [Medline: 28355612]

29. MOH Launches New App (Tetamman)to Prevent COVID-19. Saudi Ministry of Health. 2020 Apr 11. URL: https://www. moh.gov.sa/en/Ministry/MediaCenter/News/Pages/News-2020-04-11-004.aspx [accessed 2020-05-20]

30. MOH: (Tetamman) Smart Bracelet a Must for Citizens Returning from Abroad. Saudi Ministry of Health. 2020 May 22. URL: https://www.moh.gov.sa/en/Ministry/MediaCenter/News/Pages/News-2020-05-22-002.aspx [accessed 2020-05-15]

31. Tabaud App. Saudi Data and Al Authority. URL: https://tabaud.sdaia.gov.sa/IndexEn [accessed 2020-08-25]

32. National Transformation Program Delivery Plan 2018-2020. Kingdom of Saudi Arabia Vision 2030. 2018. URL: https:/ /vision2030.gov.sa/sites/default/files/attachments/NTP\%20English\%20Public\%20Document 2810.pdf [accessed 2020-08-25]

33. "Android mobile use in the unit \#Annaah_aharjh b \#Ospy_ohd in \#Almedinh_almnorh where these contribute technical monitoring of patients in \#Jaihh_korona \#Korona_aljdid". Tweet in Arabic. @ MOH_Madinah. 2020 Mar 29. URL: https:/ /twitter.com/moh madinah/status/1244384199148175361 [accessed 2020-06-25] 
34. Telemedicine Regulations in the Kingdom of Saudi Arabia. National Health Information Center (NHIC), part of the Saudi Health Council (SHC). URL: https://nhic.gov.sa/en/Initiatives/Documents/Saudi\%20Arabia\%20Telemedicine\%20Policy. pdf [accessed 2020-08-25]

35. Statistical Yearbook 2018. Kingdom of Saudi Arabia General Authority for Statistics. URL: https://www.stats.gov.sa/en/ 46 [accessed 2020-04-14]

36. Aljaber A. E-learning policy in Saudi Arabia: Challenges and successes. Res Comp Int Educ 2018 May 17;13(1):176-194. [doi: 10.1177/1745499918764147]

37. National Center for e-Learning. Webpage in Arabic. URL: https://tinyurl.com/y2dwclu2 [accessed 2020-08-25]

38. Alkhalaf S, Drew S, AlGhamdi R, Alfarraj O. E-Learning System on Higher Education Institutions in KSA: Attitudes and Perceptions of Faculty Members. Procedia Soc Behav Sci 2012;47:1199-1205. [doi: 10.1016/j.sbspro.2012.06.800]

39. E-services. Saudi Ministry of Education. URL: https://www.moe.gov.sa/en/Pages/default.aspx [accessed 2020-08-25]

40. Gharman A. Universities define mechanism of final examination, student withdrawal is an option. Saudi Arabia News. 2020 Apr 04. URL: https://www.saudi24news.com/2020/04/

universities-determine-the-mechanism-of-final-exams-student-withdrawal-is-available-saudi-arabia-news.html [accessed 2020-08-25]

41. UpToDate anywhere in Saudi Arabia. Saudi Ministry of Health. URL: https://www.scfhs.org.sa/MESPS/TrainingProgs/ EduMatActiv/Documents/UTDA\%20KSA\%20Tip\%20Sheet.pdf [accessed 2020-07-24]

42. Saudi Commission for Health Sciences eCore Courses. MDBriefcase. URL: http://www.mdbriefcase.net/SCFHS/Home. aspx [accessed 2020-08-25]

43. KFSH\&RC webinar series. King Faisal Speacilist Hospital and Research Centre. URL: https://www.kfshrc.edu.sa/en/home/ news/11097 [accessed 2020-07-24]

44. Rhythm Management During The COVID19 Pandemic Live Webinar. Saudi Heart Association. URL: https://saudi-heart. com/2020/04/12/rhythm-management-during-the-covid19-pandemic/ [accessed 2020-07-24]

45. Virtual School. Webpage in Arabic. Saudi Ministry of Education. URL: https://vschool.sa [accessed 2020-08-25]

46. Alyousef A. Offered by the Ministry of Education: multiple options in the virtual school. Al Jazirah. 2020. URL: http:/ /www.al-jazirah.com/2020/20200315/ln28.htm [accessed 2020-08-26] [WebCite Cache ID http://www.al-jazirah.com/2020/20200315/ln28.htm]

47. Virtual Learning portal Vschool.sa for distant learning. Mohammad Shatta. URL: https://www.arab-box.com/vschool-sa/ [accessed 2020-06-25]

48. "Now you can find out the updated list of applications .. delivery through registered with the body of electronic platforms by visiting the following link .. \#Klna_msaol \#Khalik_balbat" Tweet in Arabic. @ CITC_SA. 2020 Mar 28. URL: https:/ /twitter.com/citc sa/status/1243876903301394433?s=21 [accessed 2020-06-25]

49. Muawyaih AlAnsari. "Move to Tech" hashtag launches a phase of digital transformation. Webpage in Arabic. AlRiyadh Newspaper. 2020 Mar 11. URL: http://www.alriyadh.com/1809797 [accessed 2020-08-27]

50. COVID-19 Saudi Hackathon. Webpage in Arabic. URL: https://covid19saudihackathon.com [accessed 2020-08-25]

51. "The 2nd \#G20 Digital Economy Task Force meeting was held virtually under the \#G20SaudiArabia Presidency on 2 April 2020, focused on a collaborative response to \#COVID19 \& the challenges associated with the deployment of Emerging Technologies.". @g20org. 2020 Feb 04. URL: https://twitter.com/g20org/status/1245742567221858305?lang=en [accessed 2020-08-25]

52. Opening Remarks for the Custodian of the Two Holy Mosques during the Extraordinary G20 Leaders' Summit. g20.org. URL: https://g20.org/en/media/Documents/Virtual Leaders Summit King Salman Opening Remarks EN.pdf [accessed 2020-08-25]

53. Saudi Red Crescent launches “Asefni” app to request emergency service. Arab News. 2018 May 21. URL: https://www. arabnews.com/node/1306831/saudi-arabia [accessed 2020-08-25]

54. Travelling Between Cities_Online Permission Portal-Saudi Arabia. Times of KSA. 2020 Apr 04. URL: https://timesofksa. com/travelling-between-cities-online-permission-portal-saudi-arabia [accessed 2020-08-25]

55. Radcliffe DB, Bruni P. State of Social Media, Middle East: 2018. University of Oregon Scholars' Bank 2019 Jan:2018. [doi: 10.7264/FT8N-W076]

56. Saudi Ministry of Health. URL: https://www.moh.gov.sa/en/Pages/Default.aspx [accessed 2020-08-25]

57. Saudi Ministry of Health Twitter Account. Twitter. URL: https://twitter.com/SaudiMOH [accessed 2020-06-25]

58. MOH Issues COVID-19 Awareness Guidelines in Many Languages. Saudi Ministry of Health. 2020 Mar 17. URL: https:/ /www.moh.gov.sa/en/Ministry/MediaCenter/News/Pages/News-2020-03-17-001.aspx [accessed 2020-08-25]

59. The Ministry of Health denies WhatsApp's current message regarding Corona ... and explains: No. Saudi News 24.2020 Apr 11. URL: https://www.saudi24news.com/2020/04/

the-ministry-of-health-denies-whatsapps-current-message-regarding-corona-and-explains-no.html [accessed 2020-08-25]

60. Emergency risk communication (ERC) 5-step capacity-building package. World Health Organization Europe. 2017. URL: https://www.euro.who.int/en/health-topics/health-emergencies/pages/whos-work-in-emergencies/

risk-communication-in-emergencies/national-health-emergency-risk-communication-training-package [accessed 2020-08-25] 
61. @ spokesman_moh. 2020 Mar 03. URL: https://twitter.com/spokesman_moh/status/1234768772155744256 [accessed 2020-08-25]

62. Hollander JE, Carr BG. Virtually Perfect? Telemedicine for Covid-19. N Engl J Med 2020 Apr 30;382(18):1679-1681. [doi: 10.1056/nejmp2003539]

63. Prevention Ambassador Initiative 2020. Activity AoED. URL: http://alweqayah.sa/home [accessed 2020-08-25]

64. AlHkamasani M. Three million riyals fine to promote rumors of corona. Riyadh Daily. 2020 Mar 04. URL: http://www. alriyadhdaily.com/article/65c66e4c5b9240769a0d74be72cc177e [accessed 2020-03-04]

65. Alhadhira AA. "We Are All Responsible" is a Saudi swarm intelligence leadership in the face of COVID-19. SJEMed 2020:37-44. [doi: 10.24911/SJEMed/72-1589573868]

66. Corona interactive map Kingdom Of Saudi Arabia. Saudi Ministry of Health. 2020. URL: https://coronamap.sa [accessed 2020-08-25]

67. Corona Map App. Apple App Store. URL: https://apps.apple.com/app/corona-map/id1503046302 [accessed 2020-08-25]

68. COVID-19 Awareness. Saudi Ministry of Health. URL: https://covid19awareness.sa/en/home-page [accessed 2020-06-25]

69. Information About Coronavirus Disease. Waqaya Saudi Centre for Disease Prevention and Control. URL: https://covid19. cdc.gov.sa [accessed 2020-08-25]

70. COVID-19 Symptom Study app. ZOE. URL: https://covid.joinzoe.com/ [accessed 2020-08-25]

71. COVID 19 Screening Tool. Apple App Store. URL: https://www.apple.com/covid19 [accessed 2020-08-19]

72. McCall B. COVID-19 and artificial intelligence: protecting health-care workers and curbing the spread. Lancet Digit Health 2020 Apr;2(4):e166-e167. [doi: 10.1016/s2589-7500(20)30054-6]

73. Wang CJ, Ng CY, Brook RH. Response to COVID-19 in Taiwan: Big Data Analytics, New Technology, and Proactive Testing. JAMA 2020 Mar 03;323(14):1341-1342 [FREE Full text] [doi: 10.1001/jama.2020.3151] [Medline: $\underline{32125371]}$

74. Priya S. Singapore government launches COVID-19 chatbot. Singapore government launches COVID-19 chatbot, 2020. $2020 \mathrm{Feb} 24$. URL: https://www.opengovasia.com/singapore-government-launches-covid-19-chatbot/ [accessed 2020-08-25]

75. Rosenbaum E. Robotic medicine may be the weapon the world needs to combat the coronavirus. CNBC. 2020 Feb 26. URL: https://www.cnbc.com/2020/02/26/robotic-medicine-may-be-the-weapon-needed-to-combat-the-coronavirus.html [accessed 2020-08-25]

76. NAAG Urges Apple and Google to Take Further Steps to Protect Privacy of Users of COVID-19 Contact Tracing Apps. HIPPA Journal. 2020 Jun 18. URL: https://www.hipaajournal.com/ national-association-of-attorneys-general-urges-apple-and-google-exercise-control-over-covid-19-contact-tracing-apps/ [accessed 2020-06-18]

77. Zhang W, Wang Y, Yang L, Wang C. Suspending Classes Without Stopping Learning: China's Education Emergency Management Policy in the COVID-19 Outbreak. JRFM 2020 Mar 13;13(3):55 [FREE Full text] [doi: 10.3390/jrfm13030055]

78. E-learning in Saudi Universities continues the education journey for students. Webpage in Arabic. Saudi Ministry of Education. URL: https://www.moe.gov.sa/ar/news/Pages/un-c-2020-75.aspx [accessed 2020-06-20]

79. E-learning experts praise the success of the Ministry of Education and Saudi universities in transitioning to distance learning. Saudi Ministry of Education. URL: https://www.moe.gov.sa/ar/news/Pages/el-2020-u43.aspx [accessed 2020-06-25]

80. Naar I. Distance learning could be strategic choice post-coronavirus crisis: Saudi minister. Al Arabiya. 2020 Apr 20. URL: https://english.alarabiya.net/en/coronavirus/2020/04/20/

Distance-learning-could-be-strategic-choice-post-coronavirus-crisis-Saudi-minister [accessed 2020-08-25]

81. Mahmood SH, Hasan K, Colder Carras M, Labrique A. Global Preparedness Against COVID-19: We Must Leverage the Power of Digital Health. JMIR Public Health Surveill 2020 Apr 16;6(2):e18980 [FREE Full text] [doi: 10.2196/18980] [Medline: $\underline{\text { 32297868] }}$

82. Al Shalhoob A. A study report on: communication best practice in managing the COVID-19 crisis and building health awareness among individuals in the Saudi Community A case study of the Saudi ministry of health effort. Riyadh, Saudi Arabia: King Saud University; 2020. URL: https://barq-org.sa/554588 [accessed 2020-08-27]

83. Hoda J. Identification of information types and sources by the public for promoting awareness of Middle East respiratory syndrome coronavirus in Saudi Arabia. Health Educ Res 2016 Feb 26;31(1):12-23 [FREE Full text] [doi: 10.1093/her/cyv061] [Medline: 26612051]

84. Joint External Evaluation of IHR Core Capacities of the Kingdom of Saudi Arabia. World Health Organization. 2017. URL: https://www.who.int/ihr/publications/WHO-WHE-CPI-2017.25.report/en/ [accessed 2020-08-25]

85. Lohiniva A, Sane J, Sibenberg K, Puumalainen T, Salminen M. Understanding coronavirus disease (COVID-19) risk perceptions among the public to enhance risk communication efforts: a practical approach for outbreaks, Finland, February 2020. Eurosurveillance 2020 Apr 02;25(13):online. [doi: 10.2807/1560-7917.es.2020.25.13.2000317]

\section{Abbreviations}

AI: artificial intelligence

CITC: Communication and Information Technology Commission

eHealth: electronic health 
e-learning: electronic learning

e-prescription: electronic prescription

HESN: Health Electronic Surveillance Network

HIPPA: Health Insurance Portability and Accountability Act

MERS: Middle East respiratory syndrome

MERS-CoV: Middle East respiratory syndrome coronavirus

MOE: Ministry of Education

MOH: Ministry of Health

SCFHS: Saudi Commission for Health Specialties

SDAIA: Saudi Data and Artificial Intelligence Authority

STC: Saudi Telecom Company

WHO: World Health Organization

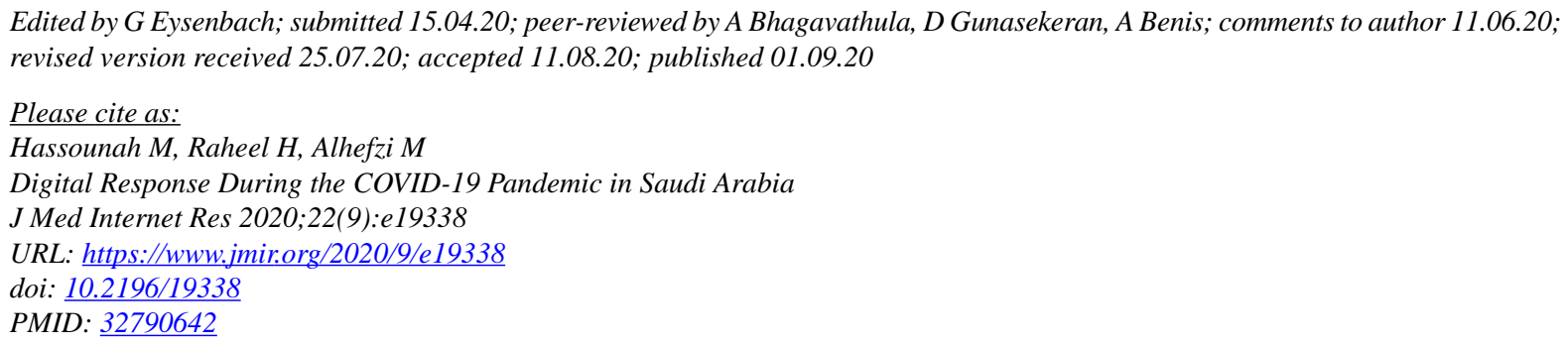

(C) Marwah Hassounah, Hafsa Raheel, Mohammed Alhefzi. Originally published in the Journal of Medical Internet Research (http://www.jmir.org), 01.09.2020. This is an open-access article distributed under the terms of the Creative Commons Attribution License (https://creativecommons.org/licenses/by/4.0/), which permits unrestricted use, distribution, and reproduction in any medium, provided the original work, first published in the Journal of Medical Internet Research, is properly cited. The complete bibliographic information, a link to the original publication on http://www.jmir.org/, as well as this copyright and license information must be included. 